\title{
Epidemiology and outcomes of geriatric and non-geriatric patients with drug allergy labels in Hong Kong
}

\author{
Philip H Li * HY Chung, CS Lau
}

\begin{abstract}
A B S T R A C T
Introduction: Adverse drug reactions are more common in geriatric patients than in younger patients, but there have been insufficient studies concerning the epidemiology or burden of drug allergy labels in geriatric patients. We prospectively investigated the prevalence and outcomes of geriatric patients with drug allergy labels in a cohort of hospitalised patients.
\end{abstract}

Methods: Patients admitted to a regional hospital over a 6-month period were recruited for this study. All patients with drug allergy labels were prospectively followed until discharge; clinical data were anonymously extracted for analyses. Patients were categorised into either geriatric (aged $\geq 65$ years) or non-geriatric (aged $<65$ years) groups. Demographic characteristics, clinical outcomes, and prevalences of drug allergy labels were compared between groups.

Results: There were 4361 admissions involving 3641 patients during the 6-month study period. Overall, 492 patients (13.5\%) had drug allergy labels, consisting of 151 non-geriatric patients (30.7\%) and 341 geriatric patients (69.3\%). The prevalence of drug allergy labels did not significantly differ between geriatric and non-geriatric patients $(13.5 \%$ vs $13.5 \%$,
$\mathrm{P}=0.976)$. Significantly more patients in the geriatric group had drug allergy labels to cardiovascular system drugs $(15.5 \%$ vs $4.6 \%, \mathrm{P}=0.001)$. Geriatric patients had a significantly lower rate of direct discharge from the hospital $(73.0 \%$ vs $88.1 \%$, $\mathrm{P}<0.001)$ and required transfers to convalescent or rehabilitation care for further management.

Conclusions: More than $13 \%$ of hospitalised geriatric patients had drug allergy labels. The leading causes of drug allergy labels were similar between geriatric and non-geriatric patients. Geriatric patients with drug allergy labels had significantly more labelled allergies to cardiovascular system drugs and adverse clinical outcomes.

\section{Hong Kong Med J 2021;27:192-7 \\ https://doi.org/10.12809/hkmj208716}

PH Li *, FHKCP, FHKAM (Medicine)

HY Chung, FHKCP, FHKAM (Medicine)

CS Lau, MD, FRCP

Division of Rheumatology and Clinical Immunology, Department of Medicine, Queen Mary Hospital, The University of Hong Kong, Hong Kong

* Corresponding author: liphilip@hku.hk

New knowledge added by this study

- More than $13 \%$ of hospitalised geriatric patients in Hong Kong had drug allergy (DA) labels.

- The most common DA labels were similar between geriatric and non-geriatric patients.

- Geriatric patients had significantly more DA labels to cardiovascular drugs and significantly lower direct discharge rates.

Implications for clinical practice or policy

- Clinicians should consider the large burden of reported DAs and associated adverse clinical outcomes among hospitalised geriatric patients, particularly with respect to antibiotic therapy and cardiovascular system drugs.

- Geriatric patients with reported DAs should be selectively referred for formal allergy workup to confirm or refute suspected DAs.

\section{Introduction}

With the continued increase in life expectancy worldwide, population ageing is an especially marked phenomenon in Asian populations. ${ }^{1}$ It has been estimated that nearly one in three individuals will be in the geriatric age-group (aged $\geq 65$ years) in Hong Kong within the next 15 years. ${ }^{2}$ Unfortunately, improved longevity is not necessarily linked with improved health or healthcare. Ageing is an unavoidable process associated with manyage-related diseases. For example, "immunosenescence"-the age-related dysregulation of the immune systemincreases geriatric patients' susceptibilities to a myriad of immune-mediated disorders (eg, infection, malignancy, and autoimmunity) and adverse reactions to medications.,

Adverse drug reactions (ADRs) are much more common in geriatric patients, such that they cause 
significant morbidity and mortality, compared with younger patients. ${ }^{5,6}$ Geriatric patients are much more likely than younger patients to be hospitalised for ADRs. ${ }^{7}$ In particular, drug allergies (DAs) comprise approximately $6 \%$ to $10 \%$ of all ADRs and up to $10 \%$ of the resulting fatal reactions. ${ }^{6}$ Despite the severe consequences of genuine DAs, many patients mistakenly report non-immune-mediated ADRs as “allergies". For example, almost $90 \%$ of patients with beta-lactam DA labels were confirmed not to be genuinely allergic in previous studies, although such incorrect DA labels were associated with a multitude of dire clinical consequences. ${ }^{8-12}$ To the best of our knowledge, although the prevalence of ADRs has been extensively reported in geriatric populations, there have been no adequate studies concerning the epidemiology or burden of DAs in geriatric patients. ${ }^{13}$ To address this lack of information, we performed a prospective analysis of the prevalence and outcomes of geriatric patients with DA labels in a cohort of hospitalised patients in Hong Kong.

\section{Methods}

All patients admitted to the acute general medical wards of Queen Mary Hospital from 1 July 2018 to 31 December 2018 were recruited for this study. The Queen Mary Hospital is the only public hospital in the Hong Kong West Cluster, which serves a population of 0.5 million and provides acute medical admissions through its Accident and Emergency Department. After admission, patients may be transferred to other convalescent or rehabilitation units of the Hong Kong West Cluster for further management if deemed unfit for direct discharge from the hospital. Patient age and sex were recorded, as was the presence of DA labels. All patients with DA labels were then followed until discharge; clinical data were anonymously extracted for analyses. Extracted clinical data included patient age and sex, presence and details of DA labels, length of stay (from the day of admission to the day of discharge [including stay at convalescent or rehabilitation hospitals] or death), and discharge outcomes (direct discharge, transfer to another hospital, or death). Details of DA labels were reviewed to ensure that the reported manifestations were consistent with the presence of clinical allergies (ie, immune-mediated hypersensitivity reactions). Manifestations suggestive of other non-immunemediated ADRs were excluded.

The DA labels were categorised in accordance with the British National Formulary classifications (if available): beta-lactam antibiotics (5.1.1 Penicillins and 5.1.2 Cephalosporins and other beta-lactams), non-beta-lactam antibiotics (5.1 Antibacterial drugs, other than 5.1.1 and 5.1.2), non-steroidal antiinflammatory drugs (10.1.1 NSAIDs), cardiovascular system (CVS) medications (2 CVS), intravenous contrast media, allopurinol, opioid analgesic (4.7.2

\section{被診斷有藥物過敏的香港老年和非老年患者的 流行病學和結果 \\ 李曦、鍾浩然、劉澤星}

引言：藥物不良反應在老年患者中比年輕患者更常見, 但有關老年患 者藥物過敏的流行病學或所造成的負擔的研究不足。這項前瞻性研究 檢視住院患者隊列中被診斷有藥物過敏的老年患者的流行率和結果。

方法：納入於地區醫院住院超過6個月的患者。對所有被診斷有藥 物過敏的患者進行前瞻性隨訪直至出院, 並以匿名方式提取臨床數據 進行分析。患者被分為老年組 (65歲或以上) 或非老年組 (65歲以 下）。比較兩組之間的人口統計學特徵、臨床結果，以及被診斷有藥 物過敏的流行率。

結果：在6個月的研究期間共有入院4361例, 涉及3641名患者。總體 而言, 492名患者 ( $13.5 \%)$ 被診斷有藥物過敏, 包括151名非老年患 者 $(30.7 \%)$ 和 341 名老年患者 $(69.3 \%)$ 。老年和非老年患者之間的被 診斷有藥物過敏流行率沒有顯著差異（13.5\%比 $13.5 \%, \mathrm{P}=0.976) 。$ 與非老年患者比較, 較多老年患者對心血管系統藥物敏感 $(15.5 \%$ 比 $4.6 \%, \mathrm{P}=0.001)$ 。老年患者的直接出院率顯著較低 $(73.0 \%$ 比 $88.1 \%$, $\mathrm{P}<0.001$ ), 需要轉介療養或復康護理作進一步治療。

結論：超過 $13 \%$ 住院老年患者被診斷有藥物過敏。老年和非老年患者 被診斷有藥物過敏的主因相若。有藥物過敏的老年患者對心血管系統 藥物的已標注過敏和不良臨床結果明顯更多。

Opioid analgesics), non-opioid analgesics (4.7.1. Non-opioid analgesics and compound prep), antihistamines (3.4.1 Antihistamines), antifungals (5.2 Antifungal drugs), or others. Patients were categorised into either geriatric (aged $\geq 65$ years) or non-geriatric (aged $<65$ years) groups. Demographic characteristics, clinical outcomes, and prevalences of DA labels were compared between groups.

The Chi squared test and independent samples $t$ tests were respectively used to compare categorical and continuous variables between groups in univariate analysis. A P value of $<0.05$ was considered statistically significant for the multivariate analysis. IBM SPSS Statistics for Windows (version 20.0; IBM Corp, Armonk [NY], Untied States) was used for all analyses. The study protocol was approved by the Institutional Review Board of the University of Hong Kong/Hospital Authority Hong Kong West Cluster.

\section{Results}

There were 4361 admissions involving 3641 patients during the 6-month study period. The male-tofemale ratio was 1:1.2. In total, 2522 patients (69.3\%) were included in the geriatric group, with mean age $71.56 \pm 17.3$ years.

In total, 492 patients (13.5\%) had DA labels, consisting of 151 non-geriatric patients (30.7\%) and 341 geriatric patients (69.3\%) [Fig 1].

The overall prevalence of DA labels did not 


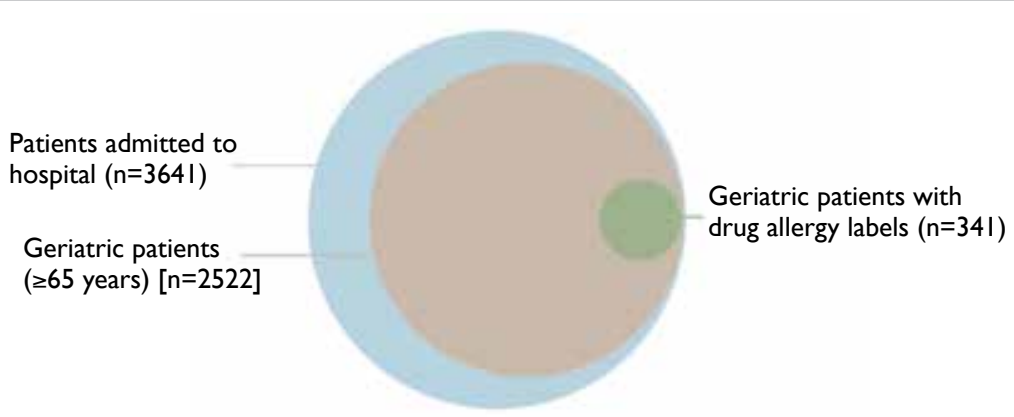

FIG I. Area proportional Venn diagram of hospitalised patients with drug allergy labels proportions of other DA labels were similar between the two groups. Patients in the geriatric group had a significantly lower rate of direct discharge from the hospital $(73.0 \%$ vs $88.1 \%, \mathrm{P}<0.001)$. The absolute mortality rate tended to be higher among patients in the geriatric group, but this difference was not statistically significant $(10.3 \%$ vs $6.0 \%, P=0.123)$.

\section{Discussion}

Although the prevalence and consequences of overall ADRs have been extensively investigated, this is the first study to specifically examine the epidemiology and outcomes of geriatric patients with DA labels. In our cohort, $13.5 \%$ of all hospitalised geriatric patients had DA labels; the leading causes of DA labels were comparable between geriatric and non-geriatric patients. Notably, there were significantly more labelled DAs to CVS medications and significantly more adverse clinical outcomes in geriatric patients.

Adverse drug reactions are defined as any "appreciably harmful or unpleasant reaction" to medications which can occur through various immunological or non-immunological mechanisms. ${ }^{14}$ Drug allergies or "hypersensitivity reactions" comprise type $B$ (non-dose-related) ADRs, which result from specific immune-mediated responses to a medication. An important problem is that many non-immune-mediated ADRs are often

TABLE. Demographic characteristics, clinical outcomes, and prevalences of drug allergy labels in geriatric and non-geriatric patients*

\begin{tabular}{|c|c|c|c|c|}
\hline & $\begin{array}{l}\text { All patients with DA } \\
\text { label, } n=492\end{array}$ & $\begin{array}{c}\text { Geriatric } \text { (aged } \geq 65 \\
\text { years), } n=341\end{array}$ & $\begin{array}{c}\text { Non-geriatric (aged } \\
<65 \text { years), } n=151\end{array}$ & $P$ value \\
\hline Female sex & $308(62.6 \%)$ & $222(65.1 \%)$ & $86(57.0 \%)$ & 0.085 \\
\hline \multicolumn{5}{|l|}{ DA labels } \\
\hline Beta-lactam antibiotics & $178(36.2 \%)$ & $131(38.4 \%)$ & $47(31.1 \%)$ & 0.121 \\
\hline Non-beta-lactam antibiotics & $123(25.0 \%)$ & $82(24.0 \%)$ & $41(27.2 \%)$ & 0.463 \\
\hline NSAIDs & $83(16.9 \%)$ & $56(16.4 \%)$ & 27 (17.9\%) & 0.690 \\
\hline CVS drugs & $60(12.2 \%)$ & $53(15.5 \%)$ & $7(4.6 \%)$ & 0.001 \\
\hline IV contrast & $39(7.9 \%)$ & $22(6.5 \%)$ & $17(11.3 \%)$ & 0.069 \\
\hline Allopurinol & $19(3.9 \%)$ & $14(4.1 \%)$ & $5(3.3 \%)$ & 0.673 \\
\hline Opioids & $7(1.4 \%)$ & $4(1.2 \%)$ & $3(2.0 \%)$ & 0.126 \\
\hline Non-opioid analgesics & $6(1.2 \%)$ & $5(1.5 \%)$ & $1(0.7 \%)$ & 0.454 \\
\hline Antihistamines & $6(1.2 \%)$ & $5(1.5 \%)$ & $1(0.7 \%)$ & 0.454 \\
\hline Antifungals & $4(0.8 \%)$ & $1(0.3 \%)$ & $3(2.0 \%)$ & 0.054 \\
\hline \multicolumn{5}{|l|}{ Outcomes } \\
\hline Length of stay, days & $12.0 \pm 19.9$ & $11.46 \pm 18.8$ & $13.1 \pm 22.1$ & 0.204 \\
\hline Recurrent admissions & $78(15.9 \%)$ & $56(16.4 \%)$ & $22(14.6 \%)$ & 0.604 \\
\hline Direct discharge from the hospital & $382(77.6 \%)$ & $249(73.0 \%)$ & 133 (88.1\%) & $<0.001$ \\
\hline Mortality & 44 (8.9\%) & $35(10.3 \%)$ & $9(6.0 \%)$ & 0.123 \\
\hline
\end{tabular}

Abbreviations: CVS = cardiovascular system; DA = drug allergy; IV = intravenous; NSAIDs = non-steroidal anti-inflammatory drugs

* Data are shown as No. (\%) or mean \pm standard deviation, unless otherwise specified 

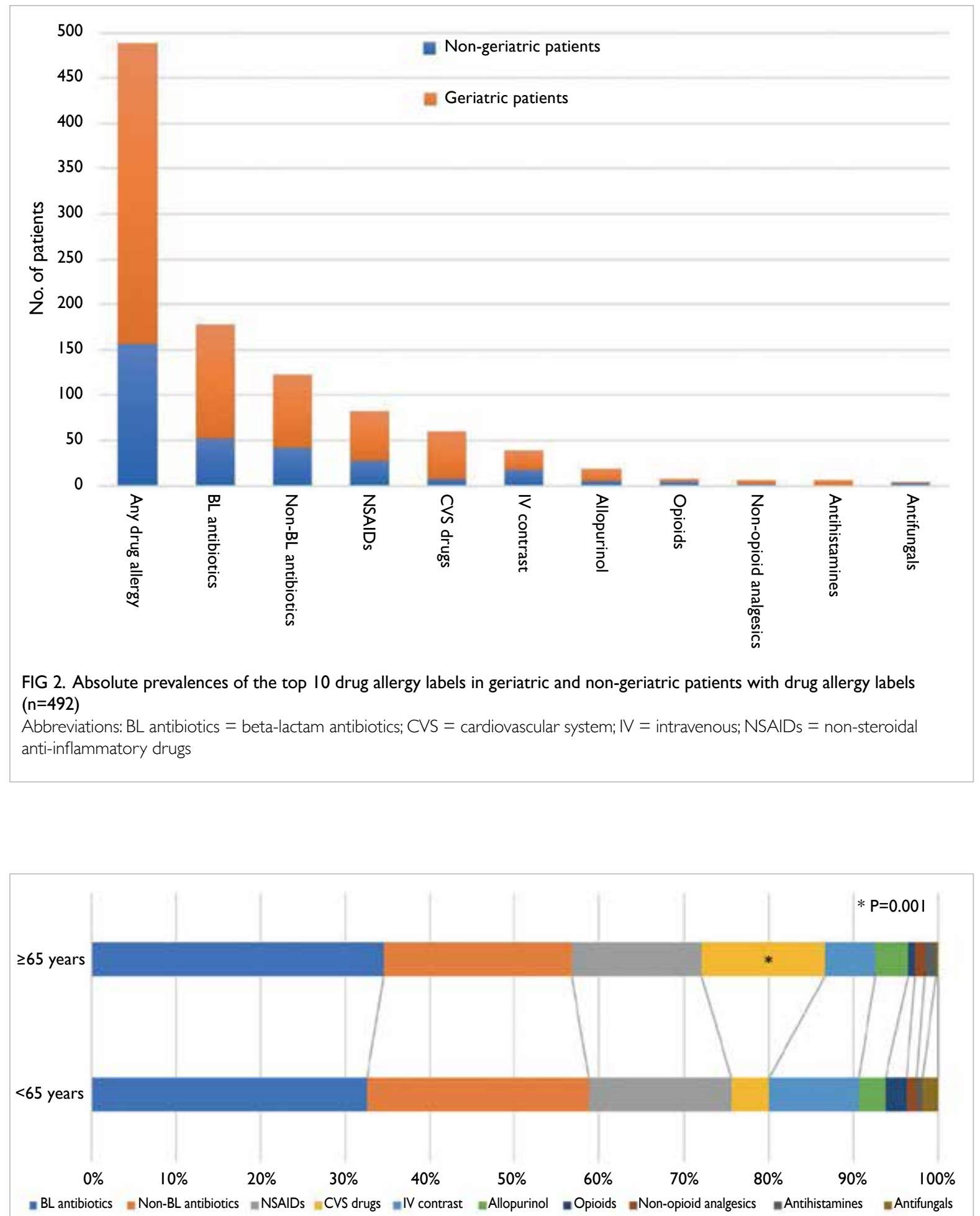

FIG 3. Proportional prevalences of the top 10 drug allergy labels in geriatric and non-geriatric patients with drug allergy labels $(n=492)$

Abbreviations: BL antibiotics = beta-lactam antibiotics; CVS = cardiovascular system; IV = intravenous; NSAIDs = non-steroidal anti-inflammatory drugs

clinically misinterpreted or incorrectly recorded as vast majority of patients with beta-lactam allergies "allergies". Although the initial DA reactions may lose skin testing sensitivity over an interval of be immunological, genuine allergies may gradually 10 years. ${ }^{15,16}$ Similarly, mild delayed (presumptively wane and warrant re-evaluation. For example, the T-cell-mediated) reactions do not consistently recur 
upon re-exposure. ${ }^{17,18}$ Often, DA labels present in the medical records of geriatric patients have not undergone appropriate allergy testing to verify whether these labels remain accurate. Geriatric patients also have had more time and events to become sensitised or develop ADRs which may be interpreted as allergies; these labels may not be entirely correct for some patients. Overall, our study confirms the presence of the high burden of DA labels in geriatric patients and corresponding worse clinical outcomes (ie, significantly lower rate of direct discharge from the hospital) compared with non-geriatric patients. This highlights the urgent need to expand the availability of allergy testing for this vulnerable population. ${ }^{19,20}$

As expected, beta-lactam antibiotics constituted the leading cause of DA labels in both patient populations in our study $(61.5 \%$ [131/213] in the geriatric group and $53.4 \%$ [47/88] in the nongeriatric group). In Hong Kong, the prevalence of reported beta-lactam antibiotic allergy is approximately $2 \%$ with a cumulative incidence approaching 10 per 100000 population. ${ }^{21}$ Betalactam DA labels are known to have clinically significant consequences including the use of broadspectrum antibiotics, enhanced microbial resistance, greater number of Clostridium difficile infections, and expansions of multidrug-resistant organisms. ${ }^{10-12}$ In Hong Kong, Chen et $\mathrm{al}^{22}$ found that the prevalence of methicillin-resistant Staphylococcus aureus was $30.1 \%$ among older adults living in residential care homes. The presence of DA labels greatly restricts the repertoire of first-line antibiotics for such patients. Beta-lactams remain the most effective first-line treatment for many bacterial infections including methicillin-sensitive Staphylococcus aureus; in agreement with our findings, the unnecessary use of alternatives leads to worse patient outcomes, especially in the vulnerable geriatric population.

Furthermore, we observed a significantly greater proportion of reported DAs to CVS drugs among geriatric patients. We postulate that this is related to the substantially greater burden of CVS diseases and exposure to CVS drugs in geriatric patients, compared with other conditions. ${ }^{23,24}$ As previously mentioned, although greater exposure to CVS drugs theoretically increases the risk of genuine DAs, "allergy" labels could be the result of incorrectly interpreted ADRs. For example, the incidences of angiotensin-converting enzyme inhibitor treatment-related cough and angioedema (non-immune-mediated ADRs) increase with age. ${ }^{25}$ Regardless of their accuracy, this greater proportion of DA labels to CVS drugs is likely to further restrict therapeutic options and elicit CVS complications in geriatric patients. The accuracies of these labels and their specific effects on CVS complications warrant dedicated studies in the future.
This study had some important limitations. First, a higher rate of other adverse clinical outcomes (such as recurrent admissions and mortality) was evident among patients in the geriatric group, although this was not statistically significant. This trend may have constituted a type II statistical analysis error due to inadequate sampling and observational design. Second, we only analysed geriatric and non-geriatric patients with DA labels, although geriatric patients may have worse clinical outcomes regardless of DA status. We were also unable to analyse individual DAs or manifestations within the CVS subgroup. Nonetheless, our findings highlight the vulnerability of this specific geriatric population and emphasise the need for future prospective studies. Third, although all DAs were recorded only after confirmation by the patients' attending doctors and reported manifestations were screened by an allergist during data collection, we were unable to ascertain the accuracy of the DA labels. Comprehensive evaluations of suspected DAs often require allergological confirmation with skin and/or drug provocation tests, which is especially difficult in frail older adults. A follow-up study to identify the impacts of genuine allergies and incorrectly interpreted adverse clinical outcomes is currently in progress. Lastly, the results of our study were from a single-centre cohort of hospitalised patients and allergy records may have been influenced by local physician practices. Additional multicentre studies, including patients in the ambulatory setting, are needed to corroborate the external validity of our findings.

To the best of our knowledge, this is the first report concerning the epidemiology and outcomes of geriatric patients with DA labels. More than $13 \%$ of hospitalised geriatric patients had DA labels; the leading causes of reported DAs in these patients were similar to those of non-geriatric patients in the same hospital. We also observed significantly more reported DAs to CVS drugs, as well as worse clinical outcomes (ie, more frequent transfer to convalescent or rehabilitation facilities) among patients in the geriatric group. Additional dedicated studies are required to confirm the burden and accuracy of DA labels among the already-vulnerable geriatric population.

\section{Author contributions}

Concept or design: PH Li.

Acquisition of data: $\mathrm{PH} \mathrm{Li}$.

Analysis or interpretation of data: PH Li, HY Chung.

Drafting of the manuscript: PH Li, CS Lau.

Critical revision of the manuscript for important intellectual content: All authors.

All authors had full access to the data, contributed to the study, approved the final version for publication, and take responsibility for its accuracy and integrity. 


\section{Conflicts of interest}

All authors have disclosed no conflicts of interest.

\section{Funding/support}

This research received no specific grant from any funding agency in the public, commercial, or not-for-profit sectors.

\section{Ethics approval}

Ethical approval was obtained from HKU/HKW Institutional Review Board of The University of Hong Kong/Hospital Authority Hong Kong West Cluster (HKU/HA HKW IRB), Ref UW 18-669.

\section{References}

1. Balachandran A, de Beer J, James KS, van Wissen L, Janssen F. Comparison of population aging in Europe and Asia using a time-consistent and comparative aging measure. J Aging Health 2020;32:340-51.

2. Census and Statistics Department, Hong Kong SAR Government. Hong Kong Population Projections 2015 Available from: https://www.censtatd.gov.hk/hkstat/sub/ sp190.jsp?productCode=B1120015. Accessed 26 May 2020.

3. PawelecG.Ageandimmunity: whatis "immunosenescence"? Exp Gerontol 2018;105:4-9.

4. De Martinis M, Sirufo MM, Ginaldi L. Allergy and aging: an old/new emerging health issue. Aging Dis 2017;8:16275.

5. Davies EA, O’Mahony MS. Adverse drug reactions in special populations-the elderly. Br J Clin Pharmacol 2015;80:796-807.

6. Lazarou J, Pomeranz BH, Corey PN. Incidence of adverse drug reactions in hospitalized patients: a meta-analysis of prospective studies. JAMA 1998;279:1200-5.

7. Muehlberger N, Schneeweiss S, Hasford J. Adverse drug reaction monitoring-cost and benefit considerations. Part I: frequency of adverse drug reactions causing hospital admissions. Pharmacoepidemiol Drug Saf 1997;6 Suppl 3:S71-7.

8. Li PH, Siew LQ, Thomas I, et al. Beta-lactam allergy in Chinese patients and factors predicting genuine allergy. World Allergy Organ J 2019;12:100048.

9. Mattingly TJ 2nd, Fulton A, Lumish RA, et al. The cost of self-reported penicillin allergy: a systematic review. J Allergy Clin Immunol Pract 2018;6:1649-54.e4.

10. MacFadden DR, LaDelfa A, Leen J, et al. Impact of reported beta-lactam allergy on inpatient outcomes: a multicenter prospective cohort study. Clin Infect Dis 2016;63:904-10.

11. Macy E, Contreras R. Health care use and serious infection prevalence associated with penicillin "allergy" in hospitalized patients: a cohort study. J Allergy Clin
Immunol 2014;133:790-6.

12. Blumenthal KG, Lu N, Zhang Y, Li Y, Walensky RP, Choi HK. Risk of meticillin resistant Staphylococcus aureus and Clostridium difficile in patients with a documented penicillin allergy: population based matched cohort study. BMJ 2018;361:k2400.

13. Ventura MT, Scichilone N, Paganelli R, et al. Allergic diseases in the elderly: biological characteristics and main immunological and non-immunological mechanisms. Clin Mol Allergy 2017;15:2.

14. Edwards IR, Aronson JK. Adverse drug reactions: definitions, diagnosis, and management. Lancet 2000;356:1255-9.

15. Trubiano JA, Adkinson NF, Phillips EJ. Penicillin allergy is not necessarily forever. JAMA 2017;318:82-3.

16. Blanca M, Romano A, Torres MJ, et al. Update on the evaluation of hypersensitivity reactions to betalactams. Allergy 2009;64:183-93.

17. Mori F, Cianferoni A, Barni S, Pucci N, Rossi ME, Novembre E. Amoxicillin allergy in children: five-day drug provocation test in the diagnosis of nonimmediate reactions. J Allergy Clin Immunol Pract 2015;3:375-80.e1.

18. Bourke J, Pavlos R, James I, Phillips E. Improving the effectiveness of penicillin allergy de-labeling. J Allergy Clin Immunol Pract 2015;3:365-74.e1.

19. Chan YT, Ho HK, Lai CK, et al. Allergy in Hong Kong: an unmet need in service provision and training. Hong Kong Med J 2015;21:52-60.

20. Lee TH, Leung TF, Wong G, et al. The unmet provision of allergy services in Hong Kong impairs capability for allergy prevention-implications for the Asia Pacific region. Asian Pac J Allergy Immunol 2019;37:1-8.

21. Li PH, Yeung HH, Lau CS, Au EY. Prevalence, incidence, and sensitization profile of beta-lactam antibiotic allergy in Hong Kong. JAMA Netw Open 2020;3:e204199.

22. Chen $\mathrm{H}, \mathrm{Au} \mathrm{KM}, \mathrm{Hsu} \mathrm{KE}$, et al. Multidrug-resistant organism carriage among residents from residential care homes for the elderly in Hong Kong: a prevalence survey with stratified cluster sampling. Hong Kong Med J 2018;24:350-60.

23. Islam MM, Valderas JM, Yen L, Dawda P, Jowsey T, McRae IS. Multimorbidity and comorbidity of chronic diseases among the senior Australians: prevalence and patterns. PLoS One 2014;9:e83783.

24. Morgan TK, Williamson M, Pirotta M, Stewart K, Myers SP, Barnes J. A national census of medicines use: a 24-hour snapshot of Australians aged 50 years and older. Med J Aust 2012;196:50-3.

25. Alharbi FF, Kholod AA, Souverein PC, et al. The impact of age and sex on the reporting of cough and angioedema with renin-angiotensin system inhibitors: a case/noncase study in VigiBase. Fundam Clin Pharmacol 2017;31:67684. 